\title{
A cross-cultural comparison using the act frequency approach (AFA) in West Germany and the United States
}

\author{
ALOIS ANGLEITNER \\ University of Bielefeld, FRG \\ DAVID M. BUSS \\ University of Michigan, USA \\ and \\ ANDREA I. DEMTRÖDER \\ University of Münster, FRG
}

Abstract

Two studies were conducted in West Germany and the United States to investigate cultural similarities and differences on features of personality assessed through act frequency methods. The first study analysed the acts considered to be central and peripheral to each of six dispositional categories: dominance, quarrelsomeness, gregariousness, submissiveness, agreeableness, and aloofness. The results indicated moderate to strong similarity between the cultures in the prototypicality structure for all categories except agreeableness, which showed little concordance. The second study examined the manifested structure of act performance as assessed through retrospective act reports. The results indicated greater similarity of act endorsements between the two sexes within each culture than between cultures within each sex. Generally, the Americans showed higher base rates than the Germans. Furthermore, over all samples, females showed lower base rates than males. The correlations between relative base rates within each of the six different categories were moderately strong between the cultures 10.56 , $\mathrm{p}<0.001)$. Analyses of the relations between the prototypicality structure and the manifested structure yielded a complex picture that was highly dependent on dispositional category. For quarrelsome acts, for example, the more central acts were reported to be performed less frequently in both cultures, while other categories showed positive correlations between base rates and prototypicality. The limitations of these studies are described, and future research directions regarding expanding the range of act

\footnotetext{
All correspondence concerning this article should be addressed to: Alois Angleitner, University of Bielefeld, Department of Psychology, Postfach 8640, D-4800 Bielefeld, 1, FRG. 
frequency methods and the number of nations in the search for personality functioning across cultures are suggested.

\section{INTRODUCTION}

Much of cross-cultural personality research has been conducted using American psychological tests adapted for use in other countries. Strategies such as back-translation and the use of bilingual samples (Brislin, Lonner and Thorndike, 1973) have been proposed as a guarantee for equivalence of the concepts tested. One implicit assumption of performing such adaptations is that the dispositions (e.g. dominance, aggressiveness) in one culture carry approximately equivalent meaning in another culture. One can examine whether the translated scale possesses equivalent reliabilities and validities; whether the links between scale scores and observer judgments show a similar pattern of relationships; and whether the scale predicts the same life outcomes.

These approaches, however, bypass a more basic set of issues regarding the equivalence of personality dispositions in different cultures. When two individuals from different cultures score high on, for instance, a measure of dominance, are the dominant acts performed by these individuals the same, similar, or conceptually equivalent? Are the same features of the concept of dominance viewed as central and peripheral across the two cultures? Do the same dispositionally-relevant acts show similar base rates of manifested occurrence across the two cultures? Is the correlational structure of act trends equivalent cross-culturally? Or do cultures differ in judgments about the centrality of acts to dispositions, the base rates of manifested performance, and the correlational structure of act trends?

These questions, posed by the act frequency approach to personality (Buss and Craik, 1980, 1981, 1983a-c, 1984), suggest intriguing new dimensions of personality functioning along which to compare and contrast different cultures.

The goal of this article is to provide a first exploration of this set of issues by conducting parallel studies within West Germany and the United States. The Wiggins (1979) circumplex model of the interpersonal domain was used as a heuristic to select six dispositions from different domains of interpersonal functioning: dominance, submissiveness, agreeableness, quarrelsomeness, gregariousness, and aloofness. The first four dispositions represent the major axes of the Wiggins circumplex model, and also emerge in numerous models of personality such as those of Leary (1957), Foa (1961), Carson (1969), and Hogan (1983). Aloofness was chosen because it poses a particularly difficult challenge to the act frequency approach. It is conceivable that this disposition consists more of the acts not performed than those performed.

Two studies were conducted. The first was designed to examine the similarities and differences in the conceptual structure of acts and dispositions. That is, are the same acts judged to be central and peripheral to each of the six dispositions in West Germany and the United States? The second study was designed to examine the manifested structure of reported performance. Are the base rates of reported performance and the correlational structure of the six dispositions similar or different across the two cultures? A third goal was to examine across these cultures the links between the prototypicality structure and the manifested structure. 


\section{STUDY 1: PROTOTYPICALITY STRUCTURE}

\section{Methods and procedure}

\section{West German subjects and procedure}

The original American act lists, each consisting of 100 acts, were translated into German (by Borkenau). The acts were printed on cards. The rating was done by sorting the cards in the respective ballot boxes on which the label of the category was printed on. Acts and traits were randomized in each session. Subjects were 20 paid students: 10 males and 10 females. Half of each sex rated acts with a male as the actor (e.g. He monopolized the conversation). The other half of each sex rated acts with a female as the actor (e.g. She monopolized the conversation). In six separate sessions, each of the 600 acts was judged for its prototypicality status on each of the six trait categories (multiple prototypicality rating). The German translations of the six traits were: dominant, unterwürfig, freundlich, streitsüchtig, gesellig, and reserviert.

\section{American subjects and procedure}

Separate samples of subjects were used to judge the prototypicality of the six sets of 100 acts [see Buss and Craik (1983a) for a preliminary report]. The sample size (in parentheses) for the six categories was as follows: dominance (79), submissiveness (47), aloofness (45), gregariousness (42), quarrelsomeness (29), and agreeableness (31). The American sample had the more restricted context of 100 acts that were initially nominated for each of the six categories separately (single prototypicality rating). The ratings were done by paper-and-pencil markings. These context differences as well as the differences in the rating procedures employed (e.g. sorting vs. marking) may bias the results in the direction that the two cultures appear more dissimilar than they actually are-a point to be taken up in the discussion. In spite of these differences, the same (translated) instructional set was used for making the prototypicality judgments [adapted from Rosch and Mervis (1975)]

This study has to do with what we have in mind when we use words which refer to categories. Let's take the word red as an example. Close your eyes and imagine a true red. Now imagine an orangish red ... imagine a purple red. Although you might still name the orange-red or the purplered with the term red, they are not as good examples of red (as clear cases of what red refers to) as the clear 'true' red. In short, some reds are redder than others.

In this specific study you are asked to judge how good an example of that category various instances of the category are. The category is agreeable (dominance, quarrelsomeness, etc.). Below are listed 100 (600) acts. You are to rate how good an example of the category each act is on a 7-point scale. A ' 7 ' means that you feel the act is a very good example of your idea of what agreeable (dominance, etc) is; a ' 1 ' means that you feel the act fits very poorly with your idea of what agreeable 
(dominance, etc.) is (or is not a member of that category at all). A '4' means that you feel that act fits moderately well. Use other numbers of the 7-point scale to indicate intermediate judgments. ${ }^{1}$

\section{Results}

For the West German sample only the single prototypicality ratings will be reported (e.g. the results for the dominant acts rated for dominance). Results concerning the multiple prototypicality ratings are reported and discussed in Demtröder (1987) and Angleitner and Demtröder (1988).

\section{Comparison of means and standard deviations}

Table 1 shows the means and standard deviations of the single prototypicality ratings of the set of 100 acts within each of the six categories, separately for males and females and separately for the West German and American samples. Inspection of these figures suggests that the subjects from the two cultures are using the 7-point scale in approximately the same fashion.

Table 1. Means (M) and standard deviations (SD) of the prototypicality ratings of 100 behavioural acts for the six trait categories (from USA and West Germany)

\begin{tabular}{lcccccccc}
\hline & \multicolumn{2}{c}{ USA } & \multicolumn{2}{c}{ FRG } & \multicolumn{2}{c}{ USA } & \multicolumn{2}{c}{ FRG } \\
Trait category & Male form. & \multicolumn{2}{c}{ Male form. } & \multicolumn{2}{c}{ Female form. } & \multicolumn{2}{c}{ Female form. } \\
& M & SD & M & SD & M & SD & M & SD \\
\hline Gregariousness & 3.90 & 1.02 & 3.82 & 1.31 & 4.04 & 0.97 & 3.96 & 1.09 \\
Dominance & 4.01 & 0.78 & 4.73 & 0.91 & 4.07 & 0.77 & 4.36 & 0.74 \\
Quarrelsomeness & 3.97 & 1.14 & 4.11 & 1.26 & 3.98 & 1.14 & 4.00 & 0.99 \\
Submissiveness & 4.07 & 0.96 & 3.79 & 1.30 & 4.10 & 0.99 & 4.12 & 1.16 \\
Aloofness & 3.35 & 1.22 & 3.79 & 1.40 & 3.42 & 1.22 & 3.59 & 1.18 \\
Agreeableness & 4.63 & 0.57 & 4.03 & 1.24 & 4.58 & 0.61 & 3.67 & 1.18 \\
\hline
\end{tabular}

Note: Ratings are made on a scale ranging from ' 1 ' (low) to ' 7 ' (high).

In general, the means varied around the scale mid-point of ' 4 ' and the standard deviations of the means were approximately ' 1 ' in both cultures and for both sexes. For the category of agreeableness, the standard deviations were extremely low for the American sample ( 0.57 for the male formulation, 0.61 for the female formulation). The means for the aloofness category tended to be lower than for the other categories, suggesting that subjects do not regard this set of acts as highly aloof.

Some differences in prototypicality ratings between the two cultures were apparent. Dominant acts were rated as slightly more prototypical by the West German subjects (4.73 for the male-as-actor, 4.36 for the female-as-actor) than by their American counterparts $(4.01,4.07)$. For agreeableness a reverse pattern was evident $(4.63$ for the male actor, 4.58 for the female actor of the American sample and 4.03 and 3.67 for the male and female actors from the West German subjects).

Two-by-two ANOVAS were calculated for each of the six categories with the factor Nation (USA vs. FRG) and Actor (male vs. female). A significant main effect

\footnotetext{
'It should be noted that for the original application in the domain of object categorization a ' 1 ' means a very good example and a ' 7 ' a very poor example.
} 
for dominance was found for nation (West Germans more dominant, $p<0.01$ ) as well as a significant interaction between nation and sex of actor $(p<0.01)$. Significant main effects for nation were also found for aloofness (West Germans higher) and agreeableness (Americans higher).

\section{Reliabilities of prototypicality judgments}

Table 2 shows the alpha reliability coefficients and mean inter-judge correlations for the panels of judges from West Germany and the United States for the male-actor and the female-actor judgments combined. The alpha coefficients ranged from 0.77 to 0.97 , suggesting adequate composite reliability within each sample. The mean inter-judge correlations were low to moderate, suggesting that subjects disagree somewhat on which acts are central and which are peripheral to each category. The lowest agreement was found for agreeableness in the American sample and for dominance in both cultures.

Table 2. Reliabilities of prototypicality judgments

\begin{tabular}{lcccc}
\hline & \multicolumn{2}{c}{ FRG } & \multicolumn{2}{c}{ USA } \\
Trait category & Alpha & Mean $r$ & Alpha & Mean $r$ \\
\hline Gregariousness & 0.93 & 0.41 & 0.95 & 0.31 \\
Dominance & 0.84 & 0.21 & 0.95 & 0.20 \\
Quarrelsomeness & 0.93 & 0.39 & 0.95 & 0.44 \\
Submissiveness & 0.92 & 0.35 & 0.96 & 0.36 \\
Aloofness & 0.91 & 0.35 & 0.97 & 0.42 \\
Agreeableness & 0.93 & 0.39 & 0.77 & 0.12 \\
\hline
\end{tabular}

Note: Mean $r$ signifies the average correlation between single judges.

\section{Comparisons of the prototypicality structure}

Table 3 shows the correlations between the West German and American mean prototypicality judgments for each of the six categories and for the male-actor version and female-actor version separately. In general, there was moderate agreement between the two cultures about which acts are central and peripheral to each category. The lowest agreement occurred for the category of agreeableness $(0.40, p<0.01$ for the male formulation; $0.30, p<0.01$ for the female formulation). In contrast, the category of quarrelsomeness shows high agreement.

Table 3. Correlations between American and West German ratings for the mean prototypicality of the 100 acts for each trait category in the male and female formulations

\begin{tabular}{lcc}
\hline Trait category & Male form. & Female form. \\
\hline Gregariousness & $0.65^{* *}$ & $0.63^{* *}$ \\
Dominance & $0.71^{* *}$ & $0.58^{* *}$ \\
Quarrelsomeness & $0.72^{* *}$ & $0.69^{* *}$ \\
Submissiveness & $0.60^{* *}$ & $0.60^{* *}$ \\
Aloofness & $0.61^{* *}$ & $0.52^{* *}$ \\
Agreeableness & $0.40^{* *}$ & $0.30^{* *}$ \\
\hline
\end{tabular}

Note: $* * p<0.01$ 
It is intriguing to examine the acts within each category that the two cultures appear to differ on in their judgments of prototypicality, especially for the category of agreeableness, since there is little agreement for that category. For example, the acts (1) He helped his friend get a job where he worked, (2) She tried to help a stranger with his problems, and (3) He skipped class to stay with a friend who needed him were judged central to agreeableness by the West German sample, but were in the lower of 50 per cent of prototypicality as judged by their American counterparts. In contrast, the acts (1) He willingly changed his opinion, (2) She compromised about where to go out to eat, and (3) He left the party when his date wanted to, even though he wanted to stay were judged to be more central by Americans than by their West German counterparts. This suggests that going beyond the call of duty in providing help is more central to agreeableness for West Germans, while yielding or submitting to the wishes of others is more central to the concept of agreeableness for Americans.

\section{Acts more central to each category}

An important product to emerge from this cross-cultural study is that the acts viewed as central to each category across the two cultures can be identified and used for further research. Thus, Tables A1-A6 (see the Appendix) show ten acts for each culture that were judged to be most central to each category, along with the means and standard deviations from both the West German and the American sample.

As shown in Table A1, there were two acts that scored in the top ten in prototypically gregarious for both samples: I threw a surprise party for a friend and I made people in a crowded elevator laugh and smile. The key difference between the two samples appears to be that the West German sample emphasized more the sociable features of gregariousness (e.g. having a few beers with friends after class), whereas the American sample emphasized more the social initiative feature of gregariousness (e.g. taking the initiative to meet neighbours, introducing self to co-workers, initiating a conversation with a stranger).

The dominant category, as shown in Table A2, had five acts that were judged to be in the top ten by both samples: I issued orders that got the group organized, I managed to control the outcome of the meeting without the others being aware of it, and I forbade her to leave the room, I set goals for the groups, and I readily used the authority of my position. Thus, both samples viewed the use of force or group goals as highly dominant, even when this might be done without others being aware of it.

Table A3 shows the most prototypical quarrelsome acts. Six acts were viewed as in the top ten in both samples: I picked a fight with the stranger at the party (the number one quarrelsome act as judged by both samples), I drew my friend into a senseless argument, I hit someone who annoyed me, I put down my friend in front of others, I danced with other men/women at the party in order to slight my date, and I wrote a hate letter to my old boyfriend/girlfriend.

Table A4 shows the most prototypical submissive acts. Three acts overlapped in the top ten: I accepted an unfair grade without questioning it (most central act of the 100 for both cultures), I accepted verbal abuse without defending myself, and I agreed that I was wrong, even though I wasn't. In both samples, submissiveness seemed to involve allowing others to abuse one without objecting or protesting. This supports the suggestion by Leary (1957) and Wiggins (1982) that submission involves masochistic tendencies. 
Table A5 shows the most prototypical aloof acts. Only one act appeared in the top ten for both samples: I sat in the corner during the party. Themes that emerge for both cultures involve avoiding others, insisting on formality, and preferring to be alone rather than an integral member of the group.

Table A6 shows the most prototypical agreeable acts. One act appeared in the top ten for both cultures: I offered an older person my seat on the bus. In spite of the cultural differences in the conception of agreeableness and although different acts appear in the top ten for these samples, the themes were somewhat similar. These included doing favours for friends and strangers, helping out others when a need is perceived, and initiating pleasant activities.

\section{Discussion}

Five of the six dispositional categories showed moderate to strong agreement between the two cultures in judgments of prototypicality structure. These findings suggest that overall, the behavioural referents for dispositional categories are similar across the two cultures. The major exception was the category of agreeableness, about which the two cultures agreed only weakly. The lower cross-cultural correlations for the agreeableness acts parallel the low reliability of the prototypicality judgments on this category in the American data [see also Borkenau (1986)].

The low cross-cultural correlations between the mean prototypicality ratings for agreeableness remain a puzzle. At least two factors could have contributed to this. First, the ratings by the American sample show tremendous range restriction and low inter-judge agreement, suggesting a lack of accurate or consensual ordering of the American acts. Second, the term 'agreeable' has two shades of meaning. The narrow sense of the word is 'agrees with things', whereas the broader sense is 'interpersonally pleasant'. It is possible that the German translation emphasized the broader meaning, whereas the American subjects adopted the narrower meaning. This interpretation is supported by the acts list in Table 3.

\section{STUDY 2: BASE RATES AND THE STRUCTURE OF REPORTED PERFORMANCE}

\section{Methods and procedures}

\section{German subjects}

The West German sample consisted of two groups. One hundred and six students (55 males and 51 females) with an age range from 16 to 25 and a mean of 22 years $(\mathrm{SD}=2.2)$ took part in this study. Also, 107 non-student subjects participated (55 males, 52 females). Here, the age range was 25-70 years with a mean of 39.9 years $(\mathrm{SD}=12.3)$. This second sample was used for checking the generalizability of our results.

\section{American subjects}

American subjects were 100 ( 53 females and 47 males). The mean age of these subjects was 20 years $(\mathrm{SD}=1.34)$. All were students at a large university in California. 


\section{Act reports}

Subjects completed a series of act reports. The instructional set for each act report was:

Below is a list of 100 acts. For each act, please indicate, first, whether or not you have ever performed it and second, if you have done so, give the best estimate of the relative frequency (seldom, sometimes, often) with which you have engaged in it. For these two questions, place an ' $\mathrm{X}$ ' over the appropriate answer.

American subjects were tested in several sessions, separated by intervals of approximately 1 week. In addition to the act reports, subjects also completed several personality scales and inventories. The West German subjects were obtained mostly through newspaper advertisements. They received their material (the six act lists and several personality scales) mostly by mail and they were requested to send it back my mail. For their participation they received a computerized personality profile by request.

\section{Results}

\section{Comparison of the category base rates}

Table 4 shows the means and standard deviations of the base rates summed across the 100 acts for each of the six categories. Overall, the base rates for the West German samples were lower than those for the American samples by an average of about four acts per category for male students and about eight acts per category for female students. The mean values for the West German non-students were slightly lower than those of the students. The lowest means were found for the female nonstudents. The category of agreeableness showed the highest base rates for all groups. Gregariousness and dominance showed the next highest base rates. Across both cultures and all groups, quarrelsome acts showed the lowest reported base rates, followed by submissiveness.

To compare the base rates of the different subgroups within the West German sample for the total of 600 acts, a two-way ANOVA was carried out with the factors Sex (male vs. female) and Sample (student vs. non-student). The student groups achieved significantly higher base rates than the non-students over all 600 acts $(p<0.01)$. Females generally showed lower base rates compared to males $(p<0.05)$. There was no significant interaction effect.

For the cross-cultural comparison, two-way ANOVAs were calculated with the factors Nation and Sex, using the base rates over all 600 acts. Over the 600 acts, a main effect for the factor Nation was significant $(p<0.01)$ with Americans showing higher base rates than West Germans.

In spite of the differences, the correlations based on all 600 acts between the West German and American base rate means ranged from $0.64(p<0.01)$ for American males vs. West German female non-students to $0.77(p<0.01)$ for the fermale students in America vs. West Germany (see Table 5). This suggests that the base rate ordering of the categories is quite similar across the two cultures.

\section{Comparisons of base rates within each category}

Table 5 shows the correlations among the base rates from the different subsamples 


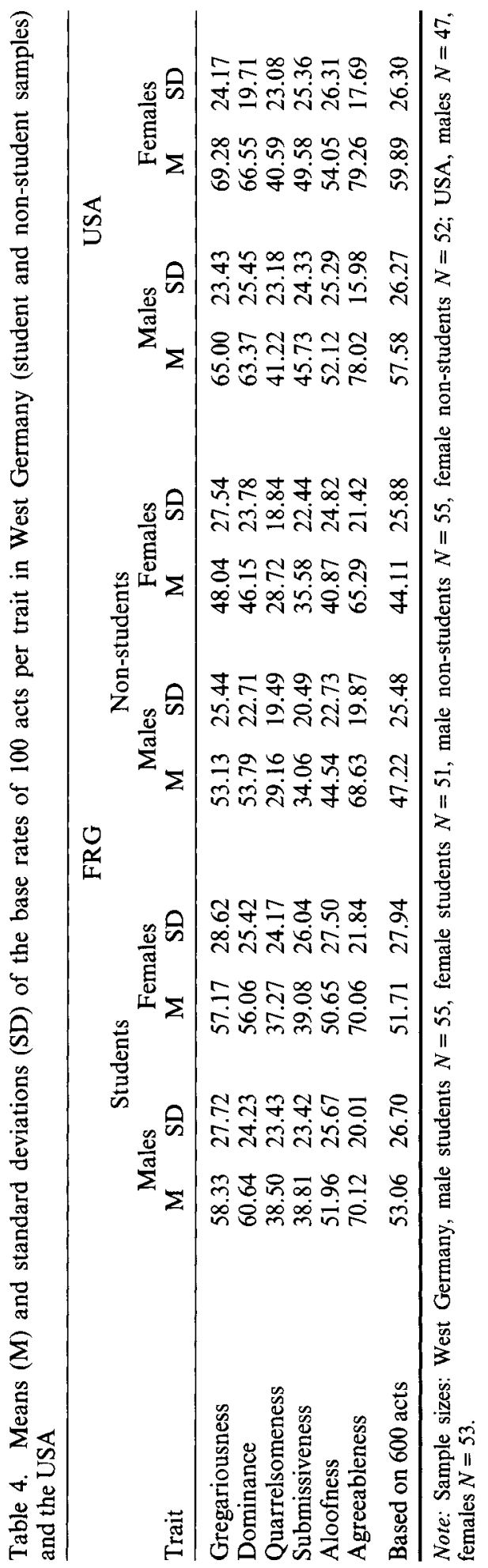




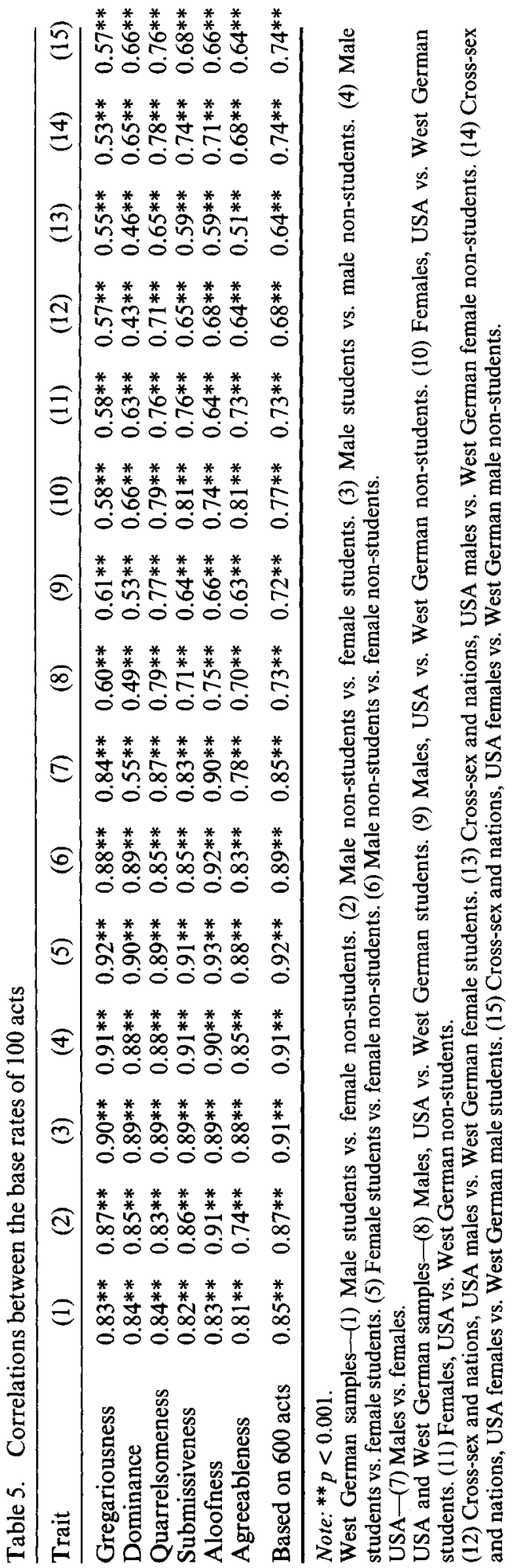


(sex, national, and cross-national comparisons) within each of the six categories separately. All correlations were moderate to strong in magnitude. The highest correlations were found for the different comparisons of the West German subsamples. They ranged from 0.85 for male vs. female students to 0.92 for female students and female non-students. Interestingly, the data showed slightly greater similarity within the two sexes ( 0.91 for the males and 0.92 for the females) in spite of their different social backgrounds, occupations, and age. The correlations for the six categories differed only slightly for the six group comparisons. However, the lowest relationship in the West German samples was found for agreeableness for the male vs. female West German student (0.74). American male and female students generally showed a similar pattern of base rates, except for dominance (0.55).

In the cross-cultural comparisons, the lowest agreement was found for two of the cross-sex comparisons: American male students vs. West German female students (0.68) and American male students vs. West German female non-students (0.64). All other coefficients ranged from 0.72 to 0.77 . Quarrelsomeness, aloofness, submissiveness, and agreeableness showed the largest similarities in the cross-cultural comparisons. Dominance and gregariousness showed moderate correlations in base rates across the different samples. In general, the data show greater similarity between males and females from the same culture than occurs between same-sex comparisons from different cultures.

\section{Comparison of the correlational structure of act composites}

Table 6 shows the inter-correlations among the act composites from the 25 most prototypical acts (Proto 1) for the two West German subsamples; below the diagonal are the correlations for the non-student sample, above are the correlations for the student sample. Table 7 shows the analogous matrix for the American sample.

There was clearly a positive manifold in all matrices. This is likely to be due to some combination of an acquiescence response set and differing general activity levels such that individuals vary in how many acts they perform regardless of the category (cf. Botwin and Buss, 1989).

In order to examine the similarities between the different correlational structures, Spearman's rho correlations were computed. Table 8 shows the rho coefficients between the matrices from the different subsamples and between these matrices and the hypothetical correlation matrix (ideal) based on Wiggins' (1979) circumplex model.

The within-FRG comparisons showed a relatively homogeneous correspondence between the samples of the same sex and those of the same occupational status. The matrices of the male and female students correlated 0.72 ; those of the male and female non-students correlated 0.75 . The correlation between the matrices of the two female samples was also 0.75 , and between those of the two male samples 0.73 . Generally lower correlations were found for the cross-sex/cross-occupation comparisons. For example, there was no significant correspondence between the matrices of the non-student females and the student males $(0.45, \mathrm{n} . \mathrm{s}$.). Concerning the cross-cultural comparisons, all West German correlation matrices showed moderate correspondence to the American sample matrix. The calculated rho values ranged from 0.53 to 0.61 . 


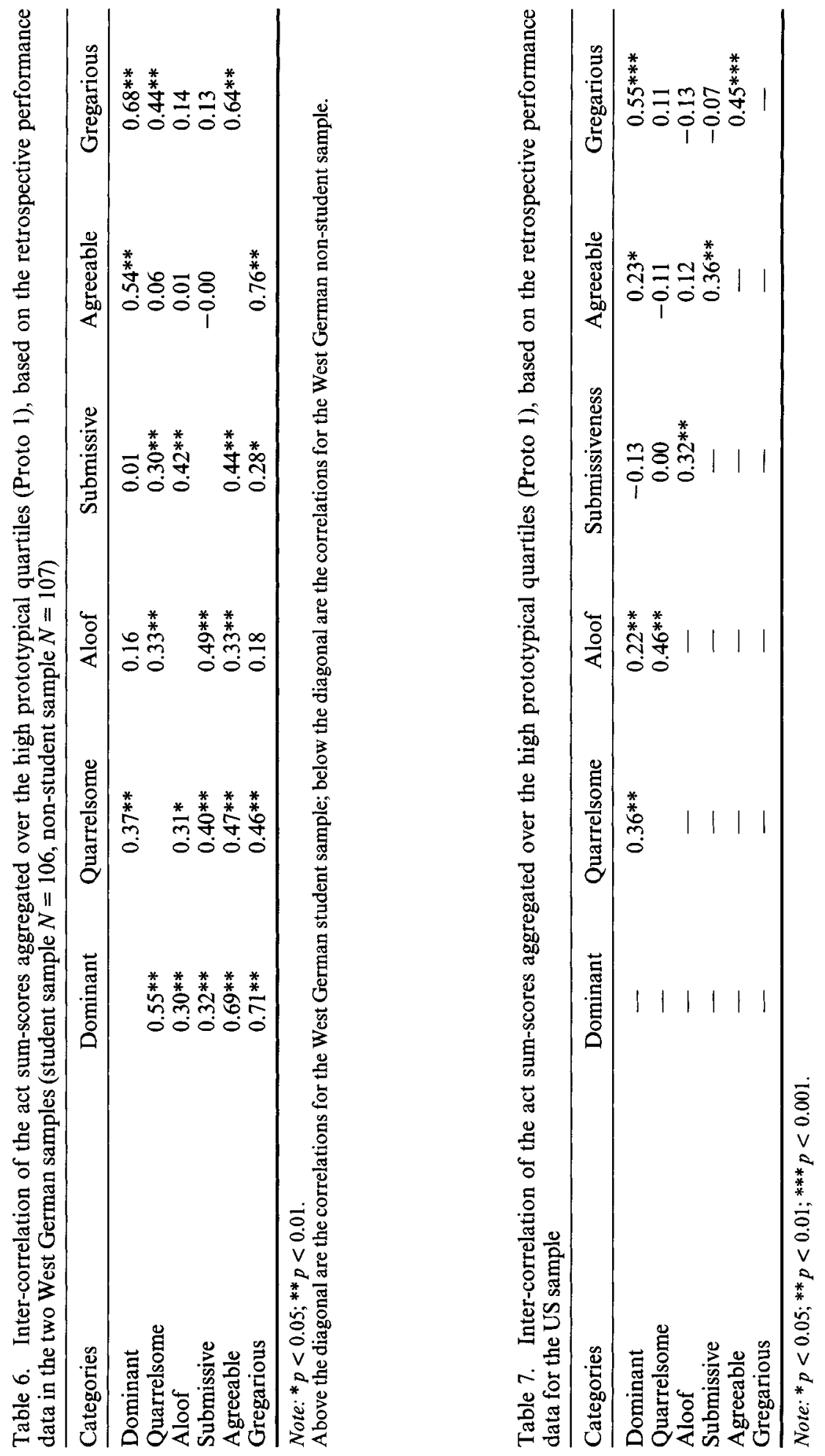


Table 8. Correlations among the base rates of the 25 highly prototypical acts (Proto 1) of the different West German subsamples, the American total sample, and the hypothetical correlation matrix (ideal) from Wiggins (1979) (Spearman's rho)

(1)

FRG students

(1) Total

(2) Male

(3) Female

FRG non-students

(4) Total

(5) Male

(6) Female

(7) USA

(8) Ideal
(2)

(3)

$0.92 * * *$

$0.92^{* * *} \quad 0.72^{* *}$

(4)

(5)

Note: $* p<0.05 ; * * p<0.01 ; * * * p<0.001$

\section{Correlations between the prototypicality ratings and the base rates}

To identify the relationship between the two different levels of category analysis, the internal and manifested structure, the correlations were calculated between the prototypicality ratings and base rates using 100 acts per category (see Table 9).

Table 9. Correlations between the prototypicality ratings and the base rates based on the 100 acts per category and the total of 600 acts

\begin{tabular}{lccccccc} 
& \multicolumn{3}{c}{ Students } & \multicolumn{2}{c}{ FRG } & \multicolumn{2}{c}{ USA } \\
& Male & Female & \multicolumn{2}{c}{ Male } & Female & Male & Female \\
\hline Gregarious & 0.11 & 0.09 & 0.19 & 0.15 & 0.06 & 0.01 \\
Dominant & 0.08 & -0.05 & $0.23^{*}$ & 0.09 & 0.19 & -0.01 \\
Quarrelsome & $-0.36^{* *}$ & $-0.29^{* *}$ & $-0.37^{* *}$ & $-0.25^{* *}$ & $-0.46^{* *}$ & $-0.31^{* *}$ \\
Submissive & $-0.23^{*}$ & $-0.23^{* *}$ & -0.16 & -0.17 & $-0.20^{*}$ & $-0.26^{* *}$ \\
Aloof & -0.14 & -0.12 & -0.11 & -0.12 & $-0.36^{* *}$ & $-0.34^{* *}$ \\
Agreeable & 0.09 & $0.22^{*}$ & 0.13 & $0.30^{* *}$ & 0.18 & 0.16 \\
Total & -0.04 & -0.09 & 0.00 & -0.03 & -0.03 & -0.06 \\
\hline
\end{tabular}

Note: ${ }^{*} p<0.05 ;{ }^{* *} p<0.01$.

The relationship between centrality of acts and their base rates of manifested performance clearly varies across dispositional categories. Quarrelsomeness, submissiveness, and aloofness show fairly consistent negative correlations, suggesting that the more central acts are performed less frequently. Agreeableness, and to a lesser extent gregariousness, show weak but consistently positive correlations, suggesting that the most prototypical acts are performed somewhat more frequently. These category differences appear to balance each other in the sense that across all 600 acts, there are no significant relationships between degree of prototypicality and base rate for any of the samples. 


\section{Discussion}

Several findings warrant further conceptual and empirical attention. First is the finding that the West German base rates were generally lower than the American base rates for most act categories. One likely explanation is that this result is an artefact of obtaining the original act nominations solely from American subjects. Thus, the acts nominated may have been more relevant to, and more frequently performed in, the American sub-culture of university undergraduates, and may be slightly less relevant to the analogous West German samples. Future research could profitably obtain act nominations from each of the cultures under study to circumvent this limitation.

A second interesting finding is that men and women from the same culture were more similar in reported act performance than were men from different cultures or women from different cultures. One possibility is that culture is a more important determinant of act performance than is biological sex per se. This interpretation accords with a recent study by Buss et al. (1990) that found culture to account for substantially more variance in mate preferences than did biological sex. Another possibility is that this finding is attributable to the particular act list, which was generated within the United States. Future research that uses act lists generated within each culture under study will permit disentangling these two explanations.

A third finding that warrants further research attention is the intriguing negative correlations between base rate and prototypicality for quarrelsomeness when contrasted with the positive correlations obtained for agreeableness and gregariousness. This makes some intuitive sense: acts of murder, which would be highly prototypically quarrelsome, are indeed performed less frequently than are less prototypically quarrelsome acts such as yelling at someone. Similarly, highly prototypical acts of agreeableness and gregariousness may simply be common occurrences in social interaction. What these results may indicate is a general relationship between the social desirability of an act and its frequency of occurrence. This is not social desirability in the sense of an artefact. Rather, it may represent a substantive finding that acts viewed as socially desirable are indeed performed more frequently in social interaction. It would seem strange if this were not true (i.e. if socially repugnant acts were more frequent). Future research could directly test this social desirability hypothesis.

\section{GENERAL DISCUSSION}

The act frequency approach to personality presents a new set of methods for comparing and contrasting different cultures. It distinguishes between two sets of issues. The first is the conceptual structure as represented by act nominations, prototypicality judgments of acts, and multiple sorting and rating of acts. These procedures assess the cognitive status of acts and their relations to dispositions. The second set of issues involve the manifested structure, as identified through assessments of act performance. This structure yields comparisons based on the base rates of acts and categories, as well as the correlational structure that emerges among the act composites. A final issue concerns the linkage between the conceptual and manifested structures.

The present report represents only the beginning of efforts to examine the structure of personality across different cultures. The results showed greater similarity than 
was anticipated in spite of the presence of several factors that are likely to have attenuated the magnitude of such similarity. Some limitations and future research directions may be noted. One limitation concerns translating acts into different languages. It seems clear that the translation process directly affected some of the base rates of the acts. For example, the aloof act 'I ordered Perrier water' was translated into 'ich bestellte Sprudelwasser'. The former acts labels a specific brand of imported water that is expensive and rarely ordered, as implied by the low base rate in the American samples. In contrast, these connotations of rarity, brand specificity, and high expense are not conveyed by the German translation, and so a much higher base rate was found for the German sample. As a first step, future research could profitably employ such procedures as back translations to minimize such translation problems.

Another limitation pertains to the context differences between the West German study and the American study in single versus multiple prototypicality rating and in sorting versus marking. We recommend that future studies adopt a consistent procedure of multiple dispositional sorting. In addition, the box sorting procedure adopted in the West German study has the advantages that it may be less biased in that subjects could not see the previous categories into which they had sorted a given act, and each subject received a random order of acts, thus eliminating any effects of order of presentation.

A further limitation, pertaining to the second study only, is that only self-reports of act performance were obtained. In the past 4 years, much research has been conducted using reports by intimate or close observers such as close friends and spouses of subjects (e.g. Buss, 1984, 1985; Buss and Craik, 1984), in addition to self-reports of act performance. Use of multiple data sources to assess act performance yields results that transcend single source limitations, and add considerably to the generality of the findings. On-line recording of behaviour represents another direction to overcome some of the shortcomings connected with the usage of retrospective act reports.

Still another limitation is that the acts used in these studies were first generated within the United States and translated into German. Ideally, the next study would contain the following steps: (1) generate act lists in each culture; (2) translate (and back-translate) each set of acts into the language appropriate for each culture; and (3) obtain multiple dispositional sortings, prototypicality judgments, and performance assessments on combined and intermingled sets of acts. These procedures would maximize the chances of discovering whatever cultural differences exist in conceptions and performances of act-based dispositions, as well as highlighting whatever act universality is associated with each disposition.

In sum, the results from these studies provide a promising beginning for the use of act frequency methods across cultures. Moderate agreement between West German and American samples on which acts are central and which are peripheral suggests a degree of cross-cultural generality to act-disposition linkages. Moderately strong similarities between the two cultures in relative base rates of reported acts suggests similarities between the two cultures in manifested performance. These similarities, however, must be interpreted in the context of important differences found between the two cultures, both with respect to which acts are seen as central to each category, and which acts show high and low reported performance. Together, these studies point to a more complex analysis of cross-cultural similarities and differences than 
can be obtained through analysis of traditional personality scale scores. Future studies could fruitfully overcome some of the limitations of the present studies, expand the range of act frequency methods employed, and enlarge the number of nations examined in the search for personality functioning across cultures.

\section{ACKNOWLEDGEMENTS}

Preparation of this article was supported by a grant from the University of Bielefeld (OZ 2766) to Alois Angleitner and by NIMH grant MH-41593-01 to David M. Buss. We gratefully acknowledge the assistance of Willibald Ruch in the data collection of some of the German act-report data. We thank Peter Borkenau, Lew Goldberg, Michael Gutmann, and Rainer Riemann for comments on an earlier draft of this article.

\section{REFERENCES}

Angleitner, A. and Demtröder, A. I. (1988). 'Acts and dispositions: a reconsideration of the act frequency approach,' European Journal of Personality, 2: 121-141.

Borkenau, P. (1986). 'Towards an understanding of trait interrelations: acts as instances of several traits', Journal of Personality and Social Psychology, 51: 371-381.

Botwin, M. D. and Buss, D. M. (1989). 'Structure of act-report data: is the five-factor model of personality recaptured?,' Journal of Personality and Social Psychology, 56: 988-1001.

Brislin, R. W., Lonner, W. J. and Thorndike, R. M. (1973). Cross-cultural Research Methods, Wiley Interscience, New York, NY.

Buss, D. M. (1984). 'Towards a psychology of person-environment (PE) correlation: the role of spouse selection', Journal of Personality and Social Psychology, 47: 361-377.

Buss, D. M. (1985). 'The temporal stability of acts, trends, and patterns'. In: Spielberger, C. D. and Butcher, N. J. (Eds), Advances in Personality Assessment, Vol. 5, pp. 165-196, Erlbaum, Hillsdale, NJ.

Buss, D. M. and Craik, K. H. (1980). 'The frequency approach of disposition: dominance and prototypically dominant acts', Journal of Personality, 48: 379-392.

Buss, D. M. and Craik, K. H. (1981). 'The act frequency analysis of interpersonal dispositions: aloofness, gregariousness, dominance, and submissiveness', Journal of Personality, 49: 174 192.

Buss, D. M. and Craik, K. H. (1983a). 'The act frequency approach to personality', Psychological Review, 90: 105-126.

Buss, D. M. and Craik, K. H. (1983b). 'Act prediction and the conceptual analysis of personality scales: indices of act density, bipolarity and extensity', Journal of Personality and Social Psychology, 45: 1081-1095.

Buss, D. M. and Craik, K. H. (1983c). 'The dispositional analysis of everyday conduct', Journal of Personality, 51: 393-412.

Buss, D. M. and Craik, K. H. (1984). 'Acts, dispositions and personality'. In: Maher, B. A. and Maher, W. B. (Eds), Progress in Experimental Personality Research: Normal Personality Processes, Vol. 13, Academic Press, New York, NY, pp. 240-300.

Buss, D. M. et al. (1990). 'International values in selecting mates: a study of 37 societies', Journal of Cross-Cultural Psychology.

Carson, R. C. (1969). Interaction Concepts of Personality, Aldine, Chicago, IL.

Demtröder, A. I. (1987). 'Replikation und Erweiterung des "Act Frequency Approach" (AFA): der 16-segmentige Circumplex interpersonaler Eigenschaften' [Replication and extension of the 'Act Frequency Approach' (AFA): the 16-segment circumplex of interpersonal traits], unpublished thesis, University of Bielefeld, FRG.

Foa, U. G. (1961). 'Convergences in the analysis of the structure of interpersonal behavior', Psychological Review, 68, 341-353. 
Hogan, R. (1983). 'Socioanalytic theory of personality'. In: Page, M. M. (Ed), 1982 Nebraska Symposium on Motivation: Personality-Current Theory and Research, University of Nebraska Press, Lincoln, NE, pp. 55-89.

Leary, T. (1957). Interpersonal Diagnosis of Personality, Ronald Press, New York, NY.

Rosch, F. and Mervis, C. B. (1975). 'Family resemblances: studies in the internal structure of categories', Cognitive Psychology, 7: 563-605.

Wiggins, J. S. (1979). 'A psychological taxonomy of trait-descriptive terms: the interpersonal domain', Journal of Personality and Social Psychology, 37: 395-412.

Wiggins, J. S. (1982). 'Circumplex models of interpersonal behavior in clinical psychology'. In: Kendall, P. C. and Butcher, J. N. (Eds), Handbook of Research Methods in Clinical Psychology, Wiley, New York, NY, pp. 193-221.

\section{APPENDIX}

Table A1. Most prototypical GREGARIOUS acts

Most gregarious acts as rated by the West German sample

\begin{tabular}{ccccl}
\hline \multicolumn{2}{c}{ FRG } & \multicolumn{2}{c}{ USA } \\
$x$ & SD & $x$ & SD & \\
\hline 5.90 & 1.48 & 4.91 & 1.24 & I threw a party \\
5.80 & 1.36 & 4.11 & 1.30 & I had a few beers with friends after class \\
5.70 & 1.26 & 3.61 & 1.47 & I spent the afternoon gossiping with friends \\
5.70 & 1.28 & 3.83 & 1.36 & I sat with friends after class \\
5.65 & 1.53 & 4.29 & 1.61 & I drank beer with a group of friends, rather than return home to study \\
5.60 & 1.85 & 5.13 & 1.44 & As host, I went out of the way to make guests comfortable \\
5.60 & 1.31 & 3.73 & 1.37 & I went on a group excursion \\
5.55 & 1.32 & 5.52 & 1.08 & I threw a surprise party for a friend \\
5.55 & 1.43 & 4.67 & 1.42 & I asked if I could come along with a group who were discussing their \\
& & & & plans for the night \\
5.45 & 1.57 & 5.55 & 1.33 & I made people in a crowded elevator laugh and smile \\
\hline
\end{tabular}

Most gregarious acts as rated by the American sample

\begin{tabular}{ccccc}
\hline \multicolumn{2}{c}{ USA } & \multicolumn{2}{c}{ FRG } \\
$x$ & SD & $x$ & SD & Act \\
\hline 5.91 & 0.94 & 5.15 & 1.69 & I took the initiative when meeting neighbours for the first time \\
5.90 & 1.12 & 4.70 & 1.93 & I introduced myself to new co-workers without hesitation \\
5.72 & 1.27 & 5.20 & 1.82 & I made myself prominent as the 'life of the party' \\
5.55 & 1.33 & 5.45 & 1.57 & I made people in a crowded elevator laugh and smile \\
5.52 & 1.08 & 5.55 & 1.32 & I threw a surprise party for a friend \\
5.50 & 1.09 & 5.15 & 1.53 & $\begin{array}{c}\text { I spent a little time with everyone at the party, rather than staying with } \\
\text { a single person }\end{array}$ \\
5.30 & 1.13 & 5.20 & 1.61 & $\begin{array}{l}\text { I chatted with strangers at the bus stop } \\
\text { I initiated a conversation with a stranger in the check-out line at the } \\
\text { supermarket }\end{array}$ \\
5.29 & 1.28 & 5.05 & 1.67 & \\
5.29 & 1.15 & 4.40 & 1.93 & I assumed the role of 'MC' at the party \\
5.26 & 1.30 & 4.45 & 1.79 & I introduced myself to the new neighbour \\
\hline
\end{tabular}




\section{Table A2. Most prototypical DOMINANT acts}

Most dominant acts as rated by the West German sample

\begin{tabular}{ccccl}
\hline \multicolumn{2}{c}{ FRG } & \multicolumn{2}{c}{ USA } \\
$x$ & SD & $x$ & SD & \\
\hline 6.20 & 0.95 & 4.41 & 2.12 & I made a final decision \\
6.00 & 1.45 & 5.24 & 1.81 & I set goals for a group \\
5.90 & 1.45 & 5.24 & 1.81 & I made decisions without consulting the others involved in them \\
5.80 & 1.32 & 5.25 & 1.89 & I forbade her to leave the room \\
5.75 & 1.83 & 4.82 & 1.85 & I was able to get the other person to do what I wished \\
5.65 & 1.18 & 4.69 & 1.71 & I told my co-worker how to do her job \\
5.60 & 1.54 & 5.29 & 1.60 & I readily used the authority of my position \\
5.50 & 1.82 & 4.89 & 1.63 & I persuaded him to do something he didn't want to do \\
5.55 & 1.76 & 5.44 & 1.72 & I managed to control the outcome of the meeting without the others being \\
& & & & aware of it \\
5.55 & 1.00 & 5.51 & 1.78 & I issued orders that got the group organized \\
\hline
\end{tabular}

Most dominant acts as rated by the American sample

\begin{tabular}{ccccl}
\hline \multicolumn{2}{c}{ USA } & \multicolumn{2}{c}{ FRG } \\
$x$ & SD & $x$ & SD & \multicolumn{1}{c}{ Act } \\
\hline 5.51 & 1.78 & 5.55 & 1.00 & I issued orders that got the group organized \\
5.44 & 1.72 & 5.55 & 1.76 & $\begin{array}{l}\text { I managed to control the outcome of the meeting without the others being } \\
\text { aware of it }\end{array}$ \\
5.43 & 1.65 & 4.30 & 1.72 & I took charge of things at the meeting \\
5.42 & 1.64 & 4.95 & 1.73 & I assigned roles and got the game going \\
5.29 & 1.60 & 5.60 & 1.54 & I readily used the authority of my position \\
5.27 & 1.80 & 5.30 & 1.81 & I took command of the situation after the accident \\
5.25 & 1.89 & 5.80 & 1.32 & I forbade her to leave the room \\
5.25 & 1.57 & 5.42 & 1.70 & I decided which programmes we would watch on TV \\
5.24 & 1.81 & 6.00 & 1.45 & I set goals for a group \\
5.20 & 1.78 & 5.55 & 1.00 & I demanded that he run an errand \\
\hline
\end{tabular}

Table A3. Most prototypical QUARRELSOME acts

Most quarrelsome acts as judged by the West German sample

\begin{tabular}{ccccl}
\hline \multicolumn{2}{c}{ FRG } & \multicolumn{2}{c}{ USA } & \\
$x$ & SD & $x$ & SD & \\
\hline 6.20 & 1.06 & 6.57 & 1.36 & I picked a fight with a stranger at the party \\
6.20 & 1.20 & 4.84 & 1.66 & I took the opposite point of view, just to be contrary \\
6.20 & 1.24 & 5.36 & 1.58 & I drew my friend into a senseless argument \\
6.00 & 1.21 & 5.41 & 1.66 & I put my friend down in front of others \\
5.80 & 1.67 & 5.00 & 1.71 & Even after he conceded the point, I continued arguing \\
5.70 & 1.80 & 6.45 & 1.46 & I hit someone who annoyed me \\
5.70 & 1.22 & 5.81 & 1.47 & I danced with other men/women at the party in order to slight my date \\
5.60 & 1.64 & 5.93 & 1.61 & I wrote a hate letter to my old boyfriend/girlfriend \\
5.55 & 1.47 & 5.26 & 1.55 & I yelled at my room-mate \\
5.50 & 1.50 & 4.75 & 1.54 & I continued talking about the subject, even after he objected \\
\hline
\end{tabular}

Most quarrelsome acts as judged by the American sample

\begin{tabular}{ccccl}
\hline \multicolumn{2}{c}{ USA } & \multicolumn{2}{c}{ FRG } & \\
$x$ & SD & $x$ & SD & \\
\hline 6.57 & 1.36 & 6.20 & 1.07 & I picked a fight with a stranger at the party \\
6.45 & 1.46 & 5.70 & 1.90 & I hit someone who annoyed me \\
6.44 & 1.59 & 5.40 & 1.96 & I slapped him when he did not agree with me \\
5.93 & 1.61 & 5.60 & 1.64 & I wrote a hate letter to my old boyfriend/girlfriend \\
5.81 & 1.47 & 5.70 & 1.22 & I danced with other men/women at the party in order to slight my date \\
5.77 & 1.73 & 3.45 & 1.76 & I cursed at my parents \\
5.64 & 1.47 & 4.60 & 1.70 & I slammed the door when I left the room \\
5.41 & 1.66 & 6.00 & 1.21 & I drew my friend into a senseless argument \\
5.35 & 1.55 & 5.35 & 1.79 & I told my friend to 'shut up' \\
\hline
\end{tabular}


Table A4. Most prototypical SUBMISSIVE acts

Most submissive acts as judged by the West German sample

\begin{tabular}{|c|c|c|c|c|}
\hline \multicolumn{2}{|c|}{ FRG } & \multicolumn{2}{|c|}{ USA } & \multirow[b]{2}{*}{ Act } \\
\hline$x$ & SD & $x$ & SD & \\
\hline 6.35 & 1.14 & 5.94 & 1.50 & I accepted an unfair grade without questioning it \\
\hline 6.20 & 1.15 & 5.33 & 1.85 & I accepted verbal abuse without defending myself \\
\hline 6.15 & 1.27 & 5.79 & 1.61 & I agreed I was wrong, even though I wasn't \\
\hline 5.95 & 1.67 & 5.17 & 1.82 & I broke off with my lover because of family pressure \\
\hline 5.85 & 1.50 & 4.25 & 1.91 & $\begin{array}{l}\text { I nodded silently when a teacher told me that he wouldn't change my } \\
\text { grade }\end{array}$ \\
\hline 5.70 & 1.38 & 4.96 & 1.64 & $\begin{array}{l}\text { I did not voice my opinion when I learned that the majority held the } \\
\text { opposite viewpoint }\end{array}$ \\
\hline 5.65 & 1.42 & 5.07 & 1.55 & $\begin{array}{l}\text { I did not tell the man to put out his cigarette, even though it bothered } \\
\text { me }\end{array}$ \\
\hline 5.60 & 1.39 & 5.19 & 1.90 & I followed my religious counsellor's instructions without question \\
\hline 5.50 & 1.40 & 4.92 & 2.49 & $\begin{array}{l}\text { I did not buy the expensive racket I wanted because it would anger my } \\
\text { parents }\end{array}$ \\
\hline 5.45 & 1.67 & 5.52 & 1.78 & I did not complain when I was overcharged at the store \\
\hline
\end{tabular}

Most submissive acts as judged by the American sample

\begin{tabular}{|c|c|c|c|c|}
\hline \multicolumn{2}{|c|}{ USA } & \multicolumn{2}{|c|}{ FRG } & \multirow[b]{2}{*}{ Act } \\
\hline$x$ & SD & $x$ & SD & \\
\hline 5.94 & 1.50 & 6.35 & 1.14 & I accepted an unfair grade without questioning it \\
\hline 5.79 & 1.61 & 6.15 & 1.27 & I agreed I was wrong, even though I wasn't \\
\hline 5.74 & 1.70 & 5.20 & 1.64 & $\begin{array}{l}\text { I did not complain when someone used my car without asking my } \\
\text { permission }\end{array}$ \\
\hline 5.54 & 1.79 & 5.45 & 1.93 & $\begin{array}{l}\text { I smoked marijuana when everyone else did even though I didn't want } \\
\text { to }\end{array}$ \\
\hline 5.52 & 1.78 & 5.45 & 1.67 & I did not complain when I was overcharged at the store \\
\hline 5.46 & 1.87 & 5.40 & 2.06 & I walked out of the store knowing that I had been shortchanged \\
\hline 5.35 & 1.91 & 3.65 & 2.48 & I allowed my lover to bring another date home \\
\hline 5.33 & 1.85 & 6.20 & 1.15 & I changed my clothes when the others made fun of my attire \\
\hline 5.32 & 1.72 & 5.35 & 1.73 & I made love with my partner when I didn't want to do so \\
\hline 5.30 & 1.51 & 4.40 & 2.01 & I let my room-mate play the stereo when I was trying to study \\
\hline
\end{tabular}

Table A5. Most prototypical ALOOF acts

Most aloof acts as judged by the West German sample

\begin{tabular}{|c|c|c|c|c|}
\hline \multicolumn{2}{|c|}{ FRG } & \multicolumn{2}{|c|}{ USA } & \multirow[b]{2}{*}{ Act } \\
\hline$x$ & SD & $x$ & $\mathrm{SD}$ & \\
\hline 6.05 & 1.00 & 4.24 & 1.06 & I offered a monosyllabic response to a conversational overture \\
\hline 6.00 & 1.12 & 4.19 & 1.72 & At the party, I answered questions about myself with curt responses \\
\hline 5.80 & 0.89 & 4.51 & 1.74 & I avoided eye contact during the conversation \\
\hline 5.60 & 1.39 & 4.67 & 1.34 & I stood apart from others during most of the cocktail party \\
\hline 5.55 & 1.28 & 5.16 & 1.60 & I sat in the corner during the party \\
\hline 5.50 & 1.54 & 3.48 & 2.00 & I chose to be alone rather than drink beer with friends \\
\hline 5.50 & 1.64 & 4.85 & 1.54 & $\begin{array}{l}\text { In the sensitivity group, I changed the topic whenever someone asked } \\
\text { me about my feelings }\end{array}$ \\
\hline 5.40 & 1.23 & 3.33 & 1.92 & $\begin{array}{l}\text { At the meeting, I pushed my chair back further from the table than the } \\
\text { others }\end{array}$ \\
\hline 5.30 & 1.63 & 3.89 & 1.42 & I waited for the new acquaintances to initiate the conversation \\
\hline 5.25 & 1.80 & 4.43 & 1.71 & I insisted that co-workers address me formally (e.g. Mr./Mrs. Smith) \\
\hline
\end{tabular}


Most aloof acts as judged by the American sample

\begin{tabular}{|c|c|c|c|c|}
\hline \multicolumn{2}{|c|}{ USA } & \multicolumn{2}{|c|}{ FRG } & \multirow[b]{2}{*}{ Act } \\
\hline$x$ & SD & $x$ & SD & \\
\hline 5.99 & 1.29 & 4.70 & 2.20 & I displayed no emotion when meeting long lost friends at the airport \\
\hline 5.78 & 1.41 & 4.80 & 2.09 & I hid in my bedroom when the others came over to visit \\
\hline 5.73 & 1.52 & 4.05 & 1.85 & $\begin{array}{l}\text { When spoken to, I seemed to feign not hearing and walked quickly away } \\
\text { in the other direction }\end{array}$ \\
\hline 5.53 & 1.53 & 2.85 & 1.76 & I told my friend I had no time for her \\
\hline 5.36 & 1.41 & 4.70 & 2.08 & I ignored the acquaintance who passed me on the street \\
\hline 5.19 & 1.76 & 4.40 & 2.28 & $\begin{array}{l}\text { I avoided someone's love-struck gaze and walked with my nose in the } \\
\text { air }\end{array}$ \\
\hline 5.16 & 1.60 & 5.55 & 1.28 & I sat in the corner during the party \\
\hline 5.15 & 1.61 & 5.15 & 1.57 & $\begin{array}{l}\text { While the other class members sat on the floor in a circle, I sat down } \\
\text { behind them near the door }\end{array}$ \\
\hline 5.13 & 1.56 & 4.85 & 2.03 & I took a route to my building that avoids encountering acquaintances \\
\hline 5.01 & 1.49 & 5.05 & 1.61 & I pretended not to see the other person in the courtyard \\
\hline
\end{tabular}

Table A6. Most prototypical AGREEABLE acts

Most agreeable acts as judged by the West German sample

\begin{tabular}{ccccl}
\hline \multicolumn{2}{c}{ FRG } & \multicolumn{2}{c}{ USA } & \\
$x$ & SD & $x$ & SD & \\
\hline 6.00 & 1.65 & 4.21 & 1.78 & I took my friend to the baseball game \\
5.90 & 1.21 & 5.50 & 1.76 & I offered an older person my seat on the bus \\
5.75 & 1.48 & 5.20 & 1.71 & I offered to help my friend move into the apartment \\
5.75 & 1.41 & 4.86 & 1.57 & I helped my friend with a different assignment \\
5.70 & 1.08 & 4.59 & 1.77 & I helped my friend get a job where I work \\
5.70 & 1.84 & 4.52 & 1.68 & I offered advice to a troubled friend \\
5.65 & 1.76 & 4.58 & 1.98 & I visited someone who I felt needed company \\
5.65 & 1.53 & 4.60 & 2.03 & I brought them flowers just to see them smile \\
5.60 & 1.43 & 4.06 & 1.89 & I hugged my friend when we met on the street \\
5.60 & 1.35 & 4.58 & 1.67 & I helped my friend fix the car \\
\hline
\end{tabular}

Most agreeable acts as judged by the American sample

\begin{tabular}{|c|c|c|c|c|}
\hline \multicolumn{2}{|c|}{ USA } & \multicolumn{2}{|c|}{ FRG } & \multirow[b]{2}{*}{ Act } \\
\hline$x$ & $\mathrm{SD}$ & $x$ & SD & \\
\hline 5.67 & 0.94 & 4.15 & 1.57 & I was willing to compromise in deciding where to go \\
\hline 5.63 & 1.37 & 3.55 & 1.96 & I attempted to arrive at a solution that was satisfactory to all involved \\
\hline 5.62 & 1.44 & 3.10 & 2.00 & I left the party when my date wanted to, even though I wanted to stay \\
\hline 5.61 & 1.21 & 5.25 & 1.59 & I did the favour without question \\
\hline 5.50 & 1.76 & 5.90 & 1.21 & I offered an older person my seat on the bus \\
\hline 5.47 & 1.47 & 3.90 & 1.80 & I did not hold a grudge against my rival \\
\hline 5.47 & 1.21 & 3.30 & 2.06 & $\begin{array}{l}\text { I willingly tried a new food at the restaurant because my friend suggested } \\
\text { it }\end{array}$ \\
\hline 5.42 & 1.29 & 3.60 & 1.93 & I accepted a 'no' for an answer, without pressing the issue \\
\hline 5.22 & 1.38 & 4.65 & 1.93 & I backed up someone who presented a good idea \\
\hline 5.21 & 1.34 & 5.35 & 1.90 & $\begin{array}{l}\text { I stopped at the post office on my way to work for my friend, even though } \\
\text { I was in a rush }\end{array}$ \\
\hline
\end{tabular}

\section{RESUME}

Deux études ont été faites en Allemagne de l'Ouest et aux États-Unis afin de recherches les similarités et les différences culturelles des traits de personnalité mesurés à l'aide de méthodes de fréquence des actes. La première étude analysait les actes qui sont considérés comme des exemples centraux et périphériques de chacune des six catégories dispositionnelles sui- 
vantes: dominance, attitude belligueuse, sociabilité, servilité, amabilité et réserve. Les résultats montrent une similarité moyenne jusque forte entre les cultures en ce qui concerne la structure des jugements prototypiques, pour toutes les catégories, à l'exception de l'amabilité. Une faible concordance a en effet été trouvée dans le cas de l'amabilité. La seconde étude avait pour but d'analyser la structure manifeste des actes accomplis, mesurée par l'intermédiaire de descriptions rétrospectives de son propre comportement. Les résultats ont montré qu'il $\mathrm{y}$ avait une plus grande similarité dans le comportement réelement montré entre les deux sexes, à l'interieur d'une certaine culture qu'entre les cultures, à l'interieur des deux sexes. Les Américains ont montré, en général de plus haut 'base rates' que les Allemands. Les femmes, d'autre part, ont montré dans tous les échantillons des 'base rates' plus bas que les hommes. Les corrélations entre les 'base rates' à l'interieur de chacune des six différentes catégories étaient modérément fortes entre les deux cultures $(0.56, p<0.001)$. Les analyses des relations entre la structure prototypique et la structure manifestée a donné une image complexe qui était fortement dépendante de la catégorie dispositionnelle. Quant aux actes belligueux, on a trouvé que dans les deux cultures les actes plus centraux étaient le moins fréquemment manifestés. Les autres catégories ont fait apparaître des corrélations positives entre 'base rates' et niveau prototypique. Les limites des cette recherche sont décrites au chapitre de la discussion; quelques lignes directrices sont également indiqueés pour la recherche future concernant la portée des méthodes de fréquence des actes ainsi que le nombre de pays à faire intervenir dans l'étude du fonctionnement de la personnalité.

\section{ZUSAMMENFASSUNG}

Es werden Untersuchungen vorgestellt, die in der Bundesrepublik Deutschland und in den Vereinigten Staaten von Amerika durchgeführt wurden, um kulturelle Ähnlichkeiten und Differenzen hinsichtlich Persönlichkeitsmerkmalen, erfaßt durch die Methoden des Verhaltensaktansatzes, zu untersuchen. In der ersten Studie wurden die Verhaltensakte hinsichtlich ihrer Prototypikalität (zentral bis peripher) für jede der folgenden sechs Eigenschaftskategorien beurteilt: Dominanz, Streitsucht, Geselligkeit, Unterwürfigkeit, Freundlichkeit und Reserviertheit. Die Ergebnisse zeigten mäßige bis hohe interkulturelle Ähnlichkeit in der Prototypikalitätsstruktur für alle Kategorien mit Ausnahme von Freundlichkeit. In dieser Kategorie läßt sich nur eine geringe Konkordanz erkennen. Die zweite Studie überprüfte die manifeste Struktur der Verhaltensaktausführungen, erfaßt mittels retrospektiver Berichte über die Ausführung dieser Verhaltensakte. Die Befunde legten eine größere Ähnlichkeit bezüglich der Aktausführungen zwischen Männern und Frauen innerhalb einer Kultur als zwischen den zwei Kulturen innerhalb einer Geschlechtsgruppe nahe. Insgesamt zeigten sich in der amerikanischen Stichprobe höhere Basisraten der Aktausführung als in den deutschen Stichproben. Des weiteren ließen Frauen im Vergleich zu Männern niedrigere Basisraten in allen Stichproben erkennen. Die Korrelationen zwischen den relativen Basisraten der beiden Kulturen waren für die sechs verschiedenen Kategorien mittelstark $(0.56, p<0.001)$.

Analysen der Beziehungen zwischen der Prototypikalitätsstruktur und der manifesten Struktur lieferten ein komplexes Ergebnismuster, welches in hohem Maße abhängig war von der jeweiligen untersuchten Eigenschaftskategorie. So wurde für Streitsuchtakte beispielsweise gefunden, daß die zentraleren Akte weniger häufig in beiden Kulturen ausgeführt wurden. Für andere Kategorien dagegen wurden positive Korrelationen zwischen Basisraten und Prototypikalität festgestellet. In der Diskussion werden Grenzen dieser Studien aufgezeigt. Als künftiges Forschungsfeld wird auf die Ausweitung des Bereichs der Methoden zum Verhaltensaktansatz sowie auf die Einbeziehung weiterer Länder für die Erforschung der Persönlichkeit verwiesen. 